\title{
Preventing Aggressive and Violent Behavior: Using Prevention Programs to Study the Role of Peer Dynamics in Maladjustment Problems
}

\author{
Pol van Lier • Frank Vitaro • Manuel Eisner
}

Published online: 8 June 2007

(C) Springer Science + Business Media B.V. 2007

\begin{abstract}
Two processes in the relationships between children have been associated with adverse developmental outcomes in children, namely, peer rejection and affiliation with deviant peers. In numerous studies, both of these processes have been linked not only to negative outcomes, including aggression, delinquency, violence, but also to school failure or internalizing problems. However, we yet have to understand the exact role of peer dynamics in the development towards maladjustment. Many prevention programs aim at manipulating peer dynamics in their effort to prevent aggression and violence. Apart from studying the effectiveness of such programs, these programs can provide valuable insight through which peer dynamics are linked with aggression and violence. In this study, we review prevention programs that studied the role of peer dynamics in the development to aggression and violent behaviors. First, we shortly describe the processes of peer rejection and deviant friends' affiliation. We then review three types of intervention programs: programs in unstructured settings, universal classroom-based programs, and targeted intervention aimed at the direct manipulation of peer processes. From these studies, we demonstrate that intervention success (and also intervention failure) is, to an extent, accounted for by peer dynamics. Implications for further research are discussed. We conclude that although preventive interventions that aim at manipulating the social context of children are promising, we should be cautious with a large-scale implementation of such programs as our knowledge of peer dynamics is yet too limited to ascertain the absence of unexpected negative effects.
\end{abstract}

Keywords Peer dynamics · Preventive interventions · Aggression · Violence · Children

P. van Lier $(\bowtie)$

Department of Developmental Psychology, Vrije Universiteit, Amsterdam, The Netherlands

e-mail: PAC.van.Lier@psy.vu.nl

F. Vitaro

Research Unit on Children's Psychosocial Maladjustment, Université de Montréal, Montréal, Canada

M. Eisner

Institute of Criminology, Cambridge University, Cambridge, UK 
There is strong cross cultural evidence that aggression and violence in childhood and adolescence are associated with an increased risk of serious maladjustment problems, including school failure, school dropout and job failure, crime and incarceration, and the development of mental disorders (Caspi et al. 1998; Moffitt et al. 1996, 2002) as well as high costs for society (Foster and Jones 2005). In addition to these negative outcomes the prevention of aggression and violence is of importance for several reasons. First, throughout the development of children and adolescents, approximately $20 \%$ of youths are at risk of developing a DSM-IV disruptive behavioral disorder, with nearly half of these children developing a conduct disorder (Costello et al. 2003). Such large numbers of children that are in need of treatment far exceeds the capacity to actually treat them. Second, many children who are in need of treatment do not receive it, even when it is available (Verhulst and van der Ende 1997), and approximately half of the children who start treatment drop out prematurely (Kazdin 1996). Third, the effectiveness of treatment programs have been shown to be limited (Kazdin 1997). Programs have therefore been developed to prevent the onset or further development of aggressive behavior and related outcomes. Many of such programs focused on the aggressive child itself or his/her family. A number of programs try to intervene in the social context in which children and adolescents operate or even included or targeted peers. The present text focuses on such programs with two specific objectives: (1) to establish our current state of knowledge with respect to the use of peers in prevention programs for aggressive children, and (2) to use the results generated from these prevention programs to stretch further our knowledge of the role of peers in the development of aggression and related antisocial behaviors.

This chapter is comprised of two parts. In the first part we will highlight the evidence from observational studies about what facets of peer contextual influences are related to the development of aggression and violence in children and adolescents, in addition to hypothesized mechanisms through which these risk variables influence aggression development. In the second part we will review the effects of a number of existing programs that aimed at manipulating the social context of children or directly used peers as intervention agents in the effort to prevent the development of aggression. In discussing these interventions, we are primarily interested in studies that shed light on how peer mechanisms may affect prevention outcomes, either by having unintended negative effects or by successfully supporting the positive outcome of a prevention trial. In particular, we distinguish between programs that intervene in relatively unstructured contexts (e.g., neighborhoods, recreation centers), universal interventions in classrooms, and targeted programs specifically for at-risk children and adolescents.

\section{Part 1}

\section{Peer Contextual Risk Variables and Behavior Problems}

Peers play an important role in the socialization of children and adolescents. Peers provide the opportunity to learn and rehearse social skills, learn to self-regulate and solve interpersonal conflict, and learn social norms, rules and processes that are involved in interpersonal relationships (Rubin et al. 1998). However, not all peer relations are beneficial for the child. In fact, some aspects of peer relations have been frequently associated with aggressive behavior and related outcomes (Coie and Dodge 1998; Rubin et al. 1998). In particular, two aspects of peer experiences may be linked in different but interrelated and equally important ways to aggressive behavior and its related outcomes. First, peers may inflict aggressive behaviors in children because they reject or victimize children, which may 
accentuate possibly already existing aggressive behavior in children (peer rejection mechanism). Second, peers may instigate and support aggressive behavior and violence by creating a context in which such behaviors are expressed, valued and thus reinforced (peer contagion mechanism).

\section{Poor Relations with the Peer Group}

As early as children come in contact with peers, they start to evaluate their behavior. As a consequence of this process, in each peer aggregate, such as classrooms, approximately 5$10 \%$ of children experience chronic rejection by peers. Processes of peer rejection have been widely reported in schoolchildren, but have also been reported in kindergarten or preschool children (Rubin et al. 1998; Snyder et al. 2004). Although peer rejection is typically defined in terms of sociometric ratings as children who receive little 'liked most' nominations, but rather many 'dislike' nominations (Coie and Kupersmidt 1983), rejecting behaviors by peers may include the exclusion and termination of social interaction and forms of overt (physical) and relational aggression (ostracism, gossiping and controlling) directed at the rejected child.

It is, however, incorrect to assume that rejected children are merely the victim of peers. Rather, their status is highly correlated with their aggressive behavior (Brendgen et al. 2001; Coie and Dodge 1998; van Lier et al. 2005a). In addition, there is evidence on a reciprocal link between peer rejection and aggressive behavior problems because Coie and Koeppl (1990) reported that aggressive rejected boys who believed that they were well accepted by newly acquainted peers showed positive behavioral adjustment.

In an attempt to study the directional effect between aggressive behavior and peer rejection a series of experimental play-group studies in which unacquainted children were observed on their emerging peer status were run (Coie and Kupersmidt 1983; Dodge 1983). The authors reported that verbal and physical aggression preceded and predicted the emergence of peer rejection in these groups. These results suggest that aggressive behavior may serve as a proximal determinant of peer rejection.

The consequences of peer rejection are serious. For instance, the experience of peer rejection has been associated with increases in externalizing (Dodge et al. 2003; Keiley et al. 2000), but also internalizing behavior problems (Deater-Deckard 2001; Keiley et al. 2000; Rubin et al. 1998) throughout the elementary school period. Moreover, peer rejection has been found to be an independent predictor of early onset conduct problems and delinquency in adolescence (Miller-Johnson et al. 1999, 2002).

\section{Pathways through which Peer Rejection Contributes to Aggression}

Knowledge about the pathways through which peer rejection may contribute to the (further) development of aggressive behavior and violence can be used to target peer rejection as a risk variable for maladjustment. One possible pathway is that through rejecting a child, the peer group is denying the child important opportunities for social growth and the development of social skills. As a result, peer rejection may cause children to have deficient social skills to adequately cope with the increasingly complex social interactions with other children. There is evidence for this. First, a number of studies demonstrated that indeed rejected children are denied from interaction (DeRosier et al. 1994; Putallaz and Wasserman 1990) and end up with less socially skilled children (Ladd 1983). Moreover some recent studies demonstrated that rejected children had social information biases and low self esteem in social situations (Dodge et al. 2003). 
Another pathway may be the interaction between the rejected child and its peers. Interactions between peers and rejected children are likely to result in negative mutual coercive exchanges, which may maintain or increase the level of externalizing behavior of the rejected child (Miller-Johnson et al. 2002; Snyder et al. 2004). For instance, Snyder and colleagues (Snyder et al. 2004) reported that the longitudinal link between kindergarten children's impulsiveness-inattention to conduct problems two years later was mediated by peer rejection and coercive exchanges with peers.

Finally, peer rejection may facilitate the rejected child's drift to other rejected children and - given its correlation with behavioral problems - aggressive peers. This may facilitate aggression because rejected children may model aggressive behavior and get reinforced for aggressive act by their peers. This process will be described in detail below.

\section{Selective Affiliation and Deviancy Training}

Although a number of children experience chronic difficulty with the larger peer group, this does not mean that these children are without friends. However, as with prosocial children, who affiliate with prosocial peers, aggressive and violent children tend to affiliate with similar aggressive friends (Boivin and Vitaro 1995). This process of homophily with respect to aggressive behavior is observed already in young children (Estell et al. 2002; Farver 1996; Snyder et al. 1997). For instance, Farver (1996) found that members of teacher-rated cliques were moderately similar in aggression, as rated by independent observers. Similarly, Snyder et al. (1997) found that out of four- and five-year-old children who were regarded as aggressive, $50 \%$ of their friends were also aggressive. Of those who were regarded as non-aggressive, only $12 \%$ of their friends were regarded as aggressive. Longitudinal evidence of selective affiliation has also been provided because children who followed chronically high antisocial behavior trajectories in childhood affiliated with increasingly antisocial friends with age (van Lier et al. 2005a). These increases in the level of aggression with respect to their friends were not matched by children who followed along any of the other developmental trajectories. Therefore, aggressive children do affiliate with other children, but their affiliation seems to be aimed at selecting similarly aggressive friends.

There is evidence that affiliation with deviant peers negatively influences a child's own level of aggression (Snyder et al. 1997; Vitaro et al. 1997). For instance, Snyder et al. (1997) reported increases in observed and teacher rated aggressive behavior among children who spent much time with aggressive friends. In contrast, children who spent little time with aggressive peers showed decreases in aggression over the follow-up period. Similarly, Vitaro et al. (1997) found that the level of delinquency at age 13 was increased only if moderately aggressive boys at age 11 and 12 affiliated with aggressive friends. Moreover, adolescents who enter gangs, indexing affiliation with severely deviant peers, have been reported to have increases in the level of aggressive and antisocial behavior (Gatti et al. 2005; Lacourse et al. 2003).

The influence of aggressive peers on a child's own level of aggression is not limited to friends. For instance, tracking elementary school children in homogeneous classrooms with respect to behavior problems may increase aggressive behavior (Kellam et al. 1998; Warren et al. 2005).

\section{Mechanism through with Affiliation with Deviant Peers Influences Aggression}

Dishion and others have conducted valuable work on providing insight in the mechanism that may explain why selective affiliation results in increases in aggressive behavior (Dishion et al. 1995a, 1996). The authors analyzed the topics and responses of 206 
adolescent male friendship dyads during conversations. They found that social reinforcement (positive affect, gesture) was strongly associated with the conversation topic. Among non-deviant dyads, social reinforcement followed normative conversation. In contrast, among deviant dyads, social reinforcement was most observed following rule-breaking conversation. The results, thus, showed that groups of deviant children tend to reinforce deviant behaviors, whereas non-deviant dyads tend to reinforce normative behaviors. The authors also found that the nature of the conversation during these laboratory sessions was strongly associated with increased rates of delinquency (Dishion et al. 1996) and tobacco, marijuana, and alcohol use (Dishion et al. 1995b). In other words, it is the learning of, and reinforcement for deviant behavior that shapes a child's own behavior, a process that is especially observed among aggressive groups. This process, called "deviancy training" has since then received substantial empirical support. For instance, Patterson et al. (2000) showed that the association between involvement with deviant peers by age 10, and growth in arrests, substance use, and sexual intercourse from age 10 to 18 was mediated by deviancy training at age 14 .

\section{Are Peers a Causal Part of the Developmental Process Linking Proximal Effects to Later Outcomes?}

Despite the evidence from the above-cited studies on the role of peers in aggressive behavior development most of those studies were correlational of design. Even longitudinal studies can only provide limited evidence on the causal role of peers in aggressive behavior development, as statistical control of all potentially confounding factors is very hard to achieve. Here randomized controlled preventive intervention trials (RCTs) offer the opportunity to test for reciprocity between risk variables and outcomes and to provide insight in the mechanisms of change in behavior (Coie and Jacobs 1993; Kellam et al. 1994). Before we move on to review empirical studies, we first outline three competing models that account for the role of peer influence in the development of problem behaviors..

\section{Theoretical Models on Peer Influence in Predicting Problem Behavior}

According to the causal ${ }^{1}$ model, rejection by normative peers and/or exposure to deviant friends play a causal role on the pathway leading some children to later maladjustment of the externalized type (e.g., delinquency, violence, conduct problems) (Elliott et al. 1985; Farrington et al. 1990; Patterson et al. 1989). These peer experiences could either mediate the link between early personal or socio-familial risk factors and later externalized problems or have an additive effect of their own. Consequently, if an early preventive intervention aimed at reducing early disruptive behaviors and improving parenting skills (i.e., the proximal outcomes) is successful in preventing later conduct problems (i.e., the distal outcome), the causal model predicts that it should have fostered social acceptance by the normative peer group and/or associations with non-deviant friends during the interval between the proximal and the distal effects. These intermediate effects would then mediate the impact of the program on later maladjustment. If peer processes totally mediate the impact of the prevention program on later outcomes, then it may be concluded, in accordance to the causal model, that peer processes are necessary and sufficient elements in the developmental chain leading to (reduced) conduct problems. Partial mediation would

\footnotetext{
${ }^{1}$ The causal model is similar to the socialization model with respect to peer contagion.
} 
suggest that they are necessary but not sufficient elements. However, a failure of the program to impact the peer processes or, alternatively, a failure of the peer processes to play a mediating role despite the success of the program on proximal and distal outcomes would cast doubt on the causal model and open the door to the incidental model.

According to proponents of the incidental $^{2}$ model, childhood disruptive behaviors independently lead to antisocial behavior and to incidental peer rejection and/or association with deviant peers (Gottfredson and Hirschi 1990). In this view, peer rejection and association with deviant friends, although a consequence of disruptive behavior, do not help explain later maladjustment (Coie et al. 1995). A relationship between these variables can exist, but this relationship is viewed as spurious and attributable to a common link with the same third variable (i.e., disruptiveness). The incidental model predicts that a reduction in early disruptive behaviors through the use of a prevention program should lead directly to less maladjustment. It could also lead to less peer rejection and to affiliation with less deviant friends, but peer acceptance or affiliation with less deviant friends should not play a role in mediating the effects of the program on later maladjustment. In other words, contrary to the causal model, peer acceptance or association with less deviant friends is neither a necessary nor a sufficient condition for the program to achieve its preventive goal.

The interactional ${ }^{3}$ model is yet another theoretical position and is intermediate to the incidental and the causal models. The interactional model posits an interaction between disruptive behavior, on the one hand, and peer rejection or deviant friends, on the other, in predicting externalizing behavior outcomes. However, there is debate about the direction of the interaction. According to Dishion and his collaborators (Dishion 1990a,b; Dishion et al. 1995) disruptive children who are rejected by their peers and/or associate with deviant friends will be at higher risk for antisocial behavior than disruptive children who are not rejected or do not affiliate with deviant friends. Hence, peer rejection and association with deviant friends are seen as moderators that amplify the link between early disruptiveness and later adjustment problems. There is, however, another interpretation of the interactional model as proposed by Vitaro et al. (1997). Here, children's disruptiveness is seen as the moderator and peers' deviancy as the moderated variable. More specifically, the influence of friends' deviancy on later maladjustment should be stronger for moderately or highly disruptive children than for the others. How these two versions of a moderated mediational pathway (Baron and Kenny 1986) could be tested through the use of preventive interventions is discussed next.

\section{Part 2}

\section{Preventive Intervention Studies}

In the following part of this chapter, we reviewed preventive intervention studies that aimed at influencing the social context in which children operate in order to reduce aggressive behavior. Apart from examining whether such programs were effective in reducing aggressive behavior and related problems, we focused on the insight these programs provide in the processes on how these programs were or were not effective (Cicchetti and Hinshaw 2002). Specifically, we examined whether the findings on the mechanisms of

\footnotetext{
${ }^{2}$ The incidental model is similar to the selection model with respect to peer contagion.

${ }^{3}$ The interactional model is similar of the enhancement model with respect to peer contagion. 
change are accordance with a causal, incidental or interactional role of peers in aggressive behavior development.

There are various ways in which aggression and violence prevention programs with a peer component may be subdivided. In the following discussion we distinguish three types of programs by the extent to which the intervention has control over the peer context. The first category comprises programs that intervene in naturally occurring groups and that have little control over the composition of the treated group. Examples are recreation centers, midnight basketball programs, or street-worker initiatives. A second type are prevention programs that intervene at the level of classrooms and schools. These programs are usually universal and use the pre-structured setting of children in classroom for delivery. Examples are universal social skills or classroom management programs. These studies can aid our understanding of peer processes in aggressive behavior development by examining whether peer relations can help to explain how proximal effects of a randomized prevention trial, such as reductions in aggressive behavior, are linked to later outcomes, such as violence, delinquency or drug use. A third type of prevention programs specifically targets at risk children and juveniles. These programs have the greatest potential to influence peer contexts that are at risk by manipulating the composition of treatment groups and hence exposure to normative, prosocial, or antisocial peers in the context of a randomized prevention trial.

\section{Prevention Programs in Unstructured Peer Contexts}

There are various violence prevention programs that operate in the relatively unstructured "natural" context of youth leisure time activities. Many programs of this type aim to keep at-risk youth away from the street, to direct them toward conventional activities and to thus prevent involvement in delinquent acts. Such programs typically offer a variety of recreational, enrichment, and leisure activities. This includes, for example, activities in youth "hang-outs", after-school recreation programs or the popular midnight basketball program (Dodge et al. 2006). Other programs focus more on shifting peer group norms, for example by attempting to channel the goals of delinquent youth gangs into more prosocial directions.

Studies that have examined such prevention programs have found widely diverging effects including iatrogenic and positive outcomes. Unfortunately, few of the existing studies in this field document details of changing peer relations, which might help to understand why effects differ so widely. However, comparison between studies suggests that differences may be related primarily to the extent to which interventions succeed in controlling unintended deviancy training processes. An early interesting example is the study by Thrasher (1936) on the effects of the New York Boys' Club, a prevention program started in 1927 with a view to taking youth away from the "demoralizing effects of the street" and providing recreational, health and vocational services to underprivileged youth. After four years Thrasher found no effect on delinquency or truancy, but found an increase in the number of offenses. Indeed, Thrasher found that delinquency rates were higher amongst those that stayed longer in the club and that "they were higher during membership periods than at times when they were not members" (p. 77). Although Thrasher was cautious saying the interpretation of these findings was unclear, this is probably the earliest finding suggesting iatrogenic effects of an intervention in unstructured peer settings.

More recently Mahoney and colleagues have presented a set of studies on recreation centers in Sweden (Mahoney et al. 2001, 2004). Although these centers do not provide specific delinquency prevention programs, they were created with the intention of keeping 
youth away from the streets and offering meaningful activities - an idea that supported the spread of youth recreation centers in many European societies. However, across various sites Mahoney and colleagues found that after controlling for various selection effects and prior risk-factors, the frequency of participation in youth recreation centers significantly increased subsequent antisocial behavior including violence. For example, a recent study examined 1,163 adolescents in a middle-sized Swedish town over a two-year period (Mahoney et al. 2004). Participants reported how often they had participated in activities of the youth recreation centers. Results showed selection effects in the sense that antisocial youths and those with poor relations to parents or school were more likely to become involved in the centers. However, after controlling for selection influences that preceded involvement in the youth centers, the frequency of youth center participation remained a strong predictor of later antisocial behavior for boys and girls. More specifically, antisocial behavior increased more amongst those who attended youth centers that aggregated many antisocial peers.

In a similar vein to recreation centers, after-school programs can be interpreted as an approach to reduce the amount of time young people spend without being supervised by adults, an important risk factor for a variety of problem behaviors. Gottfredson and colleagues have examined whether after-school programs can help to reduce delinquency amongst students in grades 4 to 8 (Gottfredson et al. 2004). They evaluated 14 after-school programs implemented as part of a delinquency and substance abuse reduction initiative in Maryland, US. The programs each served between 22 and 45 students and operated between 3 and 5 days per week. All programs included elements of academic assistance, social skills training, and recreational activities, although the mix of activities and the quality of implementation varied between sites (Gottfredson et al. 2004). Each site could choose to either implement a randomized control group/waiting list design or a comparison group design. A total of 375 students were assigned to the treatment group, 408 students were in the control group.

In contrast to the previously cited studies, this intervention was successful in reducing delinquency amongst the middle school students. However amongst primary school students no effect was observed. Examining the mediating mechanisms, the authors found that programs that were most effective put more emphasis on social skill and character development. In these programs more positive peer associations and improved attitudes pertaining towards substance use were also found as important mediating mechanisms (Gottfredson et al. 2004). Interestingly, however, the mere amount of time spent in afterschool programs was not associated with a reduction in delinquency. Gottfredson and his colleagues conclude that programs that have greater effects had incorporated structured social competency skills instruction and helped youths in coping with negative peer influences.

Potentially the most conclusive evidence on how peer contagion processes may undermine prevention efforts in relatively uncontrolled contexts comes from the St. Louis Experiment (Feldman et al. 1983). In this study Feldman and his colleagues studies 60 groups of boys in Jewish Community centers in St. Louis. These authors randomly assigned antisocial and normative boys to one of three following conditions: (1) groups in which all members were delinquent youth who had been referred to the study from social service agencies. (2) groups in which one or two delinquent youth were mixed with the normative boys, and (3) groups that consisted of normative boys only. The groups met once a week for about 2-3 hours during one school year. The intervention in these groups was relatively unstructured and consisted in a wide variety of activities offered by group leaders who had received little prior training. 
Results suggested that self-reported antisocial behavior declined in the mixed group after the intervention while the all antisocial condition increased their rate of antisocial behavior. The study also found an interaction effect in the sense that the less experienced the group leaders were in the all-delinquent groups, the larger was the increase in delinquency. However, while the study is sometimes quoted as evidence that aggregating delinquent peers in prevention efforts generally entails a high risk of iatrogenic effects, we believe a more careful interpretation is warranted. What the study demonstrates is that several moderating variables may influence delinquency training in that deviancy training is likely to occur if the intervention has little control over peer dynamics, if the treatment is unstandardized, and if the trainers are inexperienced in delivering the intervention.

Overall, we believe that findings from studies carried out in unstructured peer contexts suggest three conclusions: First, in line with the theoretical assumptions of the interactional model, they suggest that interventions in unstructured peer contexts are at a high risk selectively attracting at-risk children or adolescents and then amplify behavior tendencies through peer contagion processes during the intervention. Second, the findings on the iatrogenic effects of some of these prevention programs contradict the incidental model that assumes the correlation between association with disruptive peers and own problem behavior is spurious. Third, negative outcomes appear to be most likely in prevention programs that lack control over peer dynamics and that do not include specific skillbuilding elements. This includes, for example, recreation activities such as midnight basketball, unstructured youth recreation and learning centers, and interventions that increase the cohesiveness of gangs (Dodge et al. 2006). However, programs in unstructured environments can achieve prevention goals if they avoid aggregation of deviant and at-risk youth (thus minimizing peer contagion), retain control over peer dynamics during the intervention, provide clearly structured activities including the promotion of socialcognitive skills (hence building up protective factors), and are monitored by experienced and well-trained adults.

\section{Universal Prevention in Structured Classroom Settings}

A significant part of peer interaction from ages 5 through 16 occurs in the institutionally enforced context of schools and classes. Classrooms, therefore, constitute an opportunity for prevention to be delivered in universal yet mandatory environments. In particular, classrooms offer the unique opportunity for children to learn and practice interaction skills in a familiar environment, with a high level of formal structure, and amongst a group of children with diverse levels of social and emotional skills. Potentially, therefore, the risk of deviancy learning and peer contagion should be reduced in comparison to interventions in unstructured peer contexts. There are two main types of school-based prevention programs that have been found to be effective in preventing violence, namely classroom management programs and social-cognitive skills programs with a strong behavioral component. Both appear to be in part effective through mechanisms that impact on peer interaction patterns. Both types of preventions have a comparatively good record as being effective in reducing aggressive and antisocial behavior (see Lösel and Beelmann 2003). Yet relatively little is known about the extent to which peer dynamics mediate their effectiveness. In this section we, therefore, discuss two universal classroom interventions where relatively extensive research has examined peer dynamics.

In the respect of classroom management programs, the good behavior game (GBG) is unique in that it uses peers and classroom dynamics as a main instrument to achieve its preventive goals. The GBG was initially developed in the late 1960s and aims at promoting 
prosocial behavior and reducing aggressive and disruptive behavior (Barrish et al. 1969). At the beginning of the game, teachers discuss the necessity of behavior rules with their class and determine a set of rules for the class. Students are then assigned to three to four teams, each of which includes both disruptive and non-disruptive children. These teams play to win points or tangible rewards (e.g., stickers) if less than a set number of rule-breaking behaviors is observed by the teacher during a specified period. The GBG is only played for short periods initially and is gradually expanded during the year. Children are encouraged to actively help manage their own teammates' behavior through group reinforcement and mutual self-interest. Also, teams are reconstituted from time to time.

The effectiveness of the GBG has been studied in randomized controlled trials in the United States and the Netherlands. Outcomes of these trials demonstrated that the program had immediate and long-term effects in reducing aggressive and disruptive behavior (Dolan et al. 1993; Ialongo et al. 1999, 2001; Reid et al. 1999; van Lier et al. 2005b), and attentiondeficit/hyperactivity problems, oppositional defiant problems and conduct problems (van Lier et al. 2004) among school aged children, in addition to preventing the development of antisocial personality disorder (Petras et al. 2003) in early adulthood among at risk subjects who received the intervention in elementary school.

In addition to studying the impact of the program, van Lier et al. (2005b) also studied the processes through which reductions in aggressive/antisocial behavior occurred. First, these authors found that a decrease in antisocial behavior among children who started off on a high antisocial trajectory in the experimental classrooms was accompanied by an increasing affiliation with less antisocial peers and by a $42 \%$ reduction in the probability of experiencing peer rejection. This finding contrasted with the children on the high antisocial trajectory in the control condition. These children did not desist from their high antisocial trajectory. Moreover, they increasingly interacted with other antisocial classmates and retained their high probability of peer rejection throughout the follow-up period (i.e., from ages 8 to 11 years). Hence, the results of this study clearly support the causal model with respect to antisocial behavior on the one hand and affiliation with deviant peers and peer rejection on the other. Second, and most importantly, van Lier et al. (2005b) noted that the affiliation between normative and deviant children in the program classrooms was initiated by the normative children. Indeed, at the first post-intervention data points, it was the nondisruptive children (and more precisely the normatively developing boys) who sought the company of the improved highly disruptive classmates in the experimental condition rather than the other way around, bringing new insight on the dynamics of peer affiliation during childhood following the alleviation of disruptive behavior through a preventive intervention. Fortunately, in this study, affiliation of moderately disruptive children with initially highly disruptive children did not result in iatrogenic effects, probably because the initially disruptive children improved after their participation in the prevention program and because they were in minority compared to their classmates. Iatrogenic effects, however, do occur as detailed later.

Another successful classroom-based prevention program used both in general and special needs classes is promoting alternative thinking strategies, PATHS (Kusché and Greenberg 1994). PATHS is widely used in the United States and is currently also being implemented in the Netherlands and Switzerland. In addition, PATHS was the universal component of Fast Track, a large-scale preventive intervention study the United States (Conduct Problems Prevention Research Group 1992), in which all intervention children received PATHS and at risk children also received additional programs aimed at specific risk factors, such as peer relations. In contrast to the good behavior game, PATHS is primarily a taught curriculum. It aims at promoting emotional, cognitive, and social skills 
through lessons taught by the teacher during about 20 minutes, $2-3$ times per week. PATHS emphasizes techniques to promote positive interaction amongst students and to reduce peer rejection. For example, children are taught to adequately express and understand each others' emotions by using so-called "emotion cards" on their desks. Also, children learn problem-solving and anger management techniques that are generalized throughout the classroom and the school context. Furthermore, the "child of the week" receives particular attention and is allowed to help the teacher throughout the week.

Although PATHS has been shown to have positive effects on disruptive and aggressive behavior, the mechanisms of change and the ways in which peer dynamics are involved are not entirely clear. However, several findings suggest that PATHS effectively influences children's cognitive and behavioral scripts, which, in turn, change their patterns of interaction with peers. Greenberg and colleagues (Greenberg and Kusché 1993; Greenberg et al. 1998) for example, found that PATHS contributed to reducing problem behavior by improving the children's ability to adequately perceive their peers' emotions and to effectively solve problems in peer interactions. Further, the Fast Track project showed that for children identified at low risk, classroom levels of aggressive behavior and peer relations were improved after one year of intervention (Conduct Problems Prevention Research Group 1999). Importantly, children in FAST Track classrooms nominated fewer peers as being aggressive and indicated greater liking and fewer disliking nominations of their classmates. This suggests that PATHS may be effective to the extent that it positively influences social problem solving abilities and emotional understanding, which in turn reduce the likelihood of peer rejection and aggressive behavior. Findings from Fast Track in the high-risk samples will be discussed below, because these children received additional programs, aimed at manipulating specific risk variables.

\section{The Use of Prevention Trials to Test the Role of Peers in Aggression Development}

The evidence from both programs in unstructured settings and the universal classroom programs clearly demonstrate that it is possible and desirable to examine whether the changes produced by a randomized prevention trial in the peer domain are compatible with developmental pathways derived from competing theoretical models. In this way, preventive intervention studies, apart from their relevance for society because of their clinical effects, also provide unique insight into the causal mechanisms leading toward problem behavior development. This involves, of course, collecting data on peer processes during and after the end of the prevention program, up to the distal outcomes. Surprisingly, this is not yet a well established procedure. However, even when such variables are collected we have to be cautious with our conclusion from these findings for two reasons. First, although the initial independent variable (i.e., the prevention program) is manipulated, the mediators and the outcomes are not. In consequence, the mediators (i.e., peer rejection, friends' deviancy) and the outcomes (i.e., delinquency, drug use) may cause each other. If the mediator and the outcome variables were interchanged, the outcome would seem to "cause" the mediator, thus making impossible to distinguish between selection (i.e., delinquent children select delinquent friends) and contagion (i.e., delinquent friends influence initiation or escalation in delinquency) processes with respect to the underlying theoretical models. One way to overcome this problem would be to assess peer variables and outcome measures at each post-intervention data wave on at least two occasions. This would enable to use a bi-directional (or cross-lagged) model that could substantially aide in the teasing out of causal (or contagion) pathway(s) from incidental (or selection) pathway(s). The second reason, however, is more difficult to overcome. It refers to the problem of 
omitted mediators, also known as the mediational confound problem (Howe et al. 2002). Omitted mediators may share considerable variance with the study mediator (i.e., peers) and the distal outcome (e.g., violence/delinquency). Hence links between the latter variables may well be spurious. In other words, there may be other pathways or mediators that can explain the links between the proximal effects of a prevention program and its effect on the distal outcomes, besides peer processes (see Reynolds et al. 2004). This is especially true when the prevention program includes several components and involves many socialization agents or agencies, which is often a necessity if one wants to achieve any significant effect at all on both the proximal and the distal outcomes. The only complete solution is to specify and measure all relevant mediators and control for their effects, a task rarely achieved or even achievable. There is, fortunately, a powerful alternative to this problem: a direct manipulation of the peer processes. This alternative is illustrated next in the context of targeted group-based prevention programs.

\section{Group-based Programs with Targeted Populations}

Despite their usefulness, universal intervention have been criticized for not being costeffective because many of the involved children are not in need of additional prevention. More intensive prevention efforts are therefore often delivered in small group contexts, usually created specifically for the purpose of the delivery of the prevention program. These programs often differ in the way in which the treatment groups are composed (i.e., groups with exclusively at risk children or mixed groups where aggressive and non-aggressive children are part of the same training sessions). Such interventions run the risk of having iatrogenic effects because normative children might be negatively influenced by antisocial peers (mixed groups), or because at risk children reinforce their at risk group mates' deviant behaviors. Indeed, over the past years a number of important iatrogenic effects have been found in prevention studies in which children were aggregated into groups. Although documented mostly in the context of homogeneous antisocial groups (Dishion et al. 1999; Dodge et al. 2006), such undesirable effect have also been reported in a mixed-group setting (Mager et al. 2005) as we will describe below.

Despite their inadvertent iatrogenic effects, the studies that aggregated antisocial peers are to be valued for their theoretical implications regarding the role of peers. If antisocial children become more antisocial after participating in training sessions in the company of other antisocial peers compared, to a no intervention control group, a group receiving training sessions individually, or a group receiving training sessions in the company of nondeviant peers, then it can logically be concluded that the iatrogenic effects are the consequence of the exposure to deviant peers. This conclusion is even more convincing if process data are collected and used to illustrate the dynamics of such influence. A number of studies did precisely so. For instance Dishion and his collaborators reported a series of studies that became one of the best documented example of iatrogenic effects resulting from aggregating antisocial children together (Dishion et al. 1999, 2001; Dodge et al. 2006). Dishion and his colleagues (Dishion and Andrews 1995; Dishion et al. 1996) randomly assigned high-risk early adolescents to a group-based intervention to prevent substance use by building social-cognitive skills, a parent-group intervention, neither, or both. Although the participants in the two conditions involving the peer-group component improved in their social cognitive skills relative to the participants in the other two conditions, they also manifested more conduct problems and substance use. These results persisted two and three years after the intervention, even when informants who completely unaware of the intervention were questioned (Poulin et al. 2001). These unexpected but revealing results 
with respect to the role of peers could be explained by the process of deviancy training previously described.

Another indicated school-based program that produced revealing iatrogenic effects with respect to the role of peers is the Reconnecting Youth program, which targets high-school students who already display behavioral problems such as truancy, low school grades, drug use, and delinquency (Cho et al. 2005). In this program at risk students are grouped in classes of 10-12 students and attend a one-semester course, which is based on a detailed curriculum. The curriculum promotes skill building activities and emphasizes a positive group environment involving trust, support, confidentiality, and individual and group limit setting (Cho et al. 2005). A recent efficacy trial involving 1,218 students found that the program had negative effects on various outcomes, including a measure of anger and impulsivity. Further analyses suggest that the program had reduced bonding with conventional youth and increased bonds with youth who display high-risk behavior (i.e., drugs, alcohol, fights, truancy).

More evidence shedding light on the social dynamics involved in group interventions comes from the study by Lavallee et al. (2005) on the Friendship Groups' component of the Fast Track prevention project. This intervention involved 55 groups of 5-6 children attending first grade of primary school and being identified as belonging to the $10-15 \%$ children with the highest scores of aggressive and disruptive behavior, according to teacher and parent assessments. These Friendship Groups were run weekly after school or on weekends and utilized stories, role-plays and cooperative activities to teach and practice social skills. Lavallee and colleagues examined the extent to which individual outcomes amongst participants of the friendship groups were influenced by individual and group characteristics. Overall, they showed that the Friendship Groups achieved high levels of positive in-session behavior and that peer-escalation was typically well controlled (Lavallee et al. 2005). However, consistent with the deviancy-training hypothesis, peer reinforcement of disruptive behavior was associated with less desirable outcomes in some groups.

As part of the same Fast Track study Bierman et al. (2002) also explored whether improvements in peer rated social preference scores four years after the intervention were mediated by reductions in aggression, due to the intervention. Indeed, the authors found that improvements in social preference were, in part, mediated by reductions in teacher rated aggression. The fact that only a partial mediation was found is in accordance with the causal model but demonstrates that other processes are necessary to explain the full improvement in social preference. However, the program failed to find that reductions in affiliation with peers who used substances was mediated by the reductions in aggressive behaviors. This last result supports the incidental model and suggests that aggression is not a necessary element in the path towards affiliation with substance using peers (see Alexander et al. 2001; Allen et al. 2005 for similar results in a non-intervention context).

Evidence for deviancy training to occur in group therapies aggregating high-risk children (either together with other at risk children or with normative children) is not unequivocal. For instance, in the Metropolitan Area Child Study (MACS) one intervention condition consisted of a classroom program plus a small group intervention for high aggressive children (Metropolitan Area Child Study Research Group 2002). The small group program aimed at providing additional instruction and opportunity for practicing the skills learned in the universal component of the intervention. The results of this small group intervention showed that children appear to have adapted their individual level of aggressive behavior to the group mean level of aggression. That is, initially highly aggressive children showed decreases of such behaviors to the mean level present in the group. However, a reverse pattern was found for initially non-aggressive children who became more aggressive, up to 
level that was shared with the group aggregate (Boxer et al. 2005). Analysis of the mechanisms suggested that peer contagion processes within the small groups may have caused the increases in aggression among initially low aggressive children (Boxer et al. 2005).

The above studies tend to show that aggregating aggressive-disruptive children and adolescents may result in iatrogenic effects. A recent study by Mager and colleagues (Mager et al. 2005), however, reported divergent results. The study allocated a total of 65 sixth and seventh grade students who had increased levels externalizing problem behavior to either a "pure" at risk group (consisting of only children with increased levels of externalizing behavior) or to a "mixed" condition in which students were mixed with prosocial students at a 1:2 ratio. The intervention was highly structured and consisted of a social cognitive skills training (The Social Competence Promotion Program) that included structured discussions, worksheets and games. Also, the intervention entailed a structured behavior management during the sessions.

Surprisingly, the researchers found that participants in the pure condition had consistently better outcomes according to both teacher and parent reports than the participants in the mixed condition. Also, in session behavior was better in the pure groups as compared to the mixed groups. The study, hence, first suggests that group treatment with high-risk groups can be effective if a high implementation quality including a comprehensive behavior management strategy can be achieved. Secondly, the lower effectiveness of the program in the mixed groups was mediated by deviancy training that occurred in this group, and not, as hypothesized, in the pure group. This adds to the evidence that deviancy training mediates changes in aggressive behavior and thus supports the causal model of peer influences in aggressive behavior development.

In summary, the above described programs demonstrate that when programs aim at aggregating children (either only at risk children or at risk children together with normative children) deviancy training is likely to occur and to impede intervention effectiveness. However, as especially shown by the study by Mager et al. (2005), it is yet uncertain to which children peer contagion processes are most harmful and what influences these processes. In trying to explain their somewhat unexpected findings, Mager and colleagues hypothesize that the attenuated effects in the mixed groups may have been due to disengagement of the at risk youth in the midst of socially more competent peers. Unfortunately, the study by Mager et al. (2005) has not collected sociometric data that would allow examining whether peer rejection may have been a mediating process. Still, this is an important idea as it relates to the dynamics of peer rejection as a potential cause of problem behavior. As expressed by Dishion and Dodge (2005), "peer rejection and deviancy training are processes and they may or may not occur depending on the group dynamics created by the interaction between the participants' characteristics, the context of the intervention, and the skill of the group leader" (p. 397). Therefore, future research should be directed at exploring how peer contagion processes can be controlled.

\section{Limitations to Using Preventive Intervention Trials to Test Developmental Theory}

Before coming to conclusion on the role of preventive interventions in studying the role of peers in behavior development, we want to stress that despite their usefulness, the use of RCTs to test theoretical models has several limitations (Howe et al. 2002). First, several mediators can be triggered by a prevention program, unless only one variable is manipulated (i.e., exposure to deviant peers). This limits the power of such studies to test specific pathways of development because mediators that are not accounted for may 
influence the results, and thus may influence the validity of the conclusion based on the results. Conversely, if one aspect only is manipulated, it is not certain that the outcome (i.e., violence, delinquency or drug use) that is almost always multiply determined will be effectively altered. Depending on the quality and the intensity of the intervention, the proximal effects (i.e., peer acceptance, affiliation with non-deviant peers, better friendship quality) may not be achieved either. Absence of change on the proximal or the distal ${ }^{4}$ outcome would disqualify the use of prevention trials to test theoretical models. Hence, the situation leads to a paradox: if only one risk factor (i.e., deviant peers) is manipulated, the putative mechanisms may not be triggered and the outcome may not be altered. If, on the contrary, too many factors are manipulated, more than one mediator can be triggered and it will not be possible to attribute the possible alterations on the outcome to a single factor (i.e., affiliation with less deviant peers). Considering these limitations, $\mathrm{RCTs}^{5}$ should be considered a useful complement of longitudinal studies if one wishes to increase the plausibility of a more than correlational link between peer experiences and later adjustment and see whether the results conform to the causal, the interactional, or the incidental model.

\section{Conclusion}

The examination of peer processes, such as friendship affiliations, clique membership, and acceptance/rejection, should become standard outcomes in prevention studies targeting disruptive children (for illustrations see Conduct Problems Prevention Research Group 2004; van Lier et al. 2005b; Vitaro et al. 1999). Moreover, according to the causal and the interactional models, positive outcomes due to preventive interventions should not persist if the prevention programs did not trigger positive sides of peer processes. In consequence, these models, if confirmed, would suggest that peer processes should become a target of standard prevention/treatment programs if strong distal outcomes are to be expected. As illustrated throughout this paper, many recent prevention programs for aggressive children include a peer component where normative peers are involved as socialization agents in the hope to change aggressive children's behaviors. Preventive interventions with normative peers should be the easiest to implement and may also have the strongest impact during early childhood. In turn, it is expected that normative children's perceptions towards aggressive children will be modified if they have the opportunity to witness their newly learned skills (Conduct Problems Prevention Research Group 2002). This would open the door for new interactions initiated by the normative peers as shown in the van Lier et al. (2005b) paper. Similarly, it would prove useful to try to mitigate the tendency for aggressive children to form deviant cliques. In this respect, it may prove easier to manipulate factors that reduce the propensity of aggressive children to affiliate with each other rather than trying to modify these affiliations after they have been established. Again this would be expected especially in early childhood. In that respect, studies that experimentally manipulate factors that predict peer affiliation or factors that might moderate the influence of deviant peers are needed; they will help overcome the

\footnotetext{
${ }^{4}$ Shrout and Bolger (2002) proposed a procedure that does not require a significant effect of a prevention program on a distal outcome to test for mediation when there is a priori belief that the effect size is small or a suppression effect may exist.

${ }^{5} \mathrm{~A}$ randomized prevention trial is requested because any quasi-experimental alternative cannot offer a total control of third variables that might confound the link between the program and the proximal effects (i.e., the mediators).
} 
correlational nature of most of the peer relationships that have already been established. Two specific elements in need of examination in such experimental manipulations under the form of preventive interventions are (1) the optimal combination of deviant and non-deviant peers in such contexts and (2) the conditions to maximize positive influences (i.e., by maximizing positive group dynamics) and avoid negative contagion (i.e., by minimizing deviancy training, competition, social segregation, or exclusion).

In order to come to effective prevention programs, the Institute of Medicine (1994) identified five stages:

1. identification of a problem or disorder

2. the identification of risk and protective factors

3. carrying out pilot efficacy studies

4. launching and evaluating large-scale effectiveness trials

5. dissemination of the program in various community settings

In light of this five-step process, where do the prevention programs that involve peers as targets or socialization agents fit? As we described in the first part of this chapter, there is ample evidence from observational research that demonstrates that peer risk variables are correlated with aggressive behavior development and related maladjustment (steps 1 \& 2). We also demonstrated that preventive interventions that focus on the social context in which children operate can effectively reduce aggressive behavior problems and reduce the risk of associated maladjustment problems. Unfortunately, not all children benefit from preventive interventions, and, even worse, some children have negative outcomes due to intervention.

We can, therefore, conclude that the five steps as proposed by the Institute of Medicine may be too optimistic. For example, a feedback loop after step 3 (pilot efficacy studies) should be made to ensure that the results of the efficacy trial are still in accordance with the theoretical risk and protective processes on which the program is based (step 2). Despite their limitations, preventive intervention studies may nevertheless be the best proof for this, taken that the hypothesized mediators are operationalized and tested explicitly. Only when the program has triggered the putative mediating factors and that these factors indeed mediated the impact of the program on distal outcomes as hypothesized, does this warrant moving on to launching large scale effectiveness trials (step 4) and large scale dissemination of the programs. In all other cases, the risk of iatrogenic or short lived effects are real.

With regard to peer influences on aggressive behavior, the conclusion may be that our current knowledge warrants preventive intervention trials that would correspond to small scale efficacy trials as suggested by step 3, but not more. We know what risk variables from the peer context are relevant and how they might operate. There is even evidence from prevention studies that these risk variables indeed mediate the reported positive effects of the program on aggressive behavior development and related outcomes. However, not all results are supportive of this causal model because failures to find mediation have also been reported. Moreover, as we demonstrated, the influence of peer risk variables may be in ways yet not understood. Finally, we do not have sufficient insight in moderating variables that affect the influence of peer risk variables on behavior development. Possibly as a consequence of these gaps in our knowledge, iatrogenic effects of programs using peers as their tool of intervention have been reported to frequently occur (Dodge et al. 2006). Therefore, when implementing prevention program aimed at the peer context, we should be aware of what we know (and do not know) about peer dynamics. We should avoid programs that have been shown to trigger negative dynamics of peer rejection and peer 
contagion, but instead consider programs that make positive use of peer dynamics. Finally, we have to make certain that we measure peer dynamics and other mediating processes when implementing a RCT in these programs to enhance our understanding of the mechanisms, and the moderators of these mechanisms, through which peer risk variables influence aggressive behavior. Only after this knowledge is acquired, should we move to large scale dissemination of programs aimed at using peers in their effort to prevent maladjustment.

\section{References}

Alexander, C., Piazza, M., Mekos, D., \& Valente, T. (2001). Peers, schools, and adolescent cigarette smoking. Journal of Adolescent Health, 29, 22-30.

Allen, J. P., Porter, M. R., McFarland, F. C., Marsh, P., \& McElhaney, K. (2005). The two faces of adolescents' success with peers: Adolescent popularity, social adaptation, and deviant behavior. Child Development, 76, 747-760.

Baron, R. M., \& Kenny, D. A. (1986). The moderator-mediator variable distinction in social psychological research: Conceptual, strategic, and statistical considerations. Journal of Personality and Social Psychology, 51, 1173-1182.

Barrish, H. H., Saunders, M., \& Wolfe, M. D. (1969). Good behavior game: Effects of individual contingencies for group consequences and disruptive behavior in the classroom. Journal of Applied Behavior Analysis, 2, 119-124.

Bierman, K. L., Coie, J. D., Dodge, K. A., Greenberg, M. T., Lochman, J. E., McMahon, R. J., et al. (2002). Using the fast track randomized prevention trial to test the early-starter model of the development of serious conduct problems. Development and Psychopathology, 14, 925-943.

Boivin, M., \& Vitaro, F. (1995). The impact of peer relationships on aggression in childhood: Inhibition through coercion or promotion through peer support. In J. McCord (Ed.), Coercion and punishment in long-term perspectives (pp. 183-197). New York, NY: Cambridge University Press.

Boxer, P., Guerra, N. G., Huesmann, L. R., \& Morales, J. (2005). Proximal peer-level effects of a smallgroup selected prevention on aggression in elementary school children: An investigation of the peer contagion hypothesis. Journal of Abnormal Child Psychology, 33, 325-338.

Brendgen, M., Vitaro, F., Bukowski, W. M., Doyle, A. B., \& Markiewicz, D. (2001). Developmental profiles of peer social preference over the course of elementary school: Associations with trajectories of externalizing and internalizing behavior. Developmental Psychology, 37, 308-320.

Caspi, A., Moffitt, T. E., Newman, D. L., \& Silva, P. A. (1998). Behavioral observations at age 3 years predict adult psychiatric disorders: Longitudinal evidence from a birth cohort. In M. E. Hertzig \& E. A. Farber (Eds.), Annual progress in child psychiatry and child development: 1997 (pp. 319-331). Bristol, PA, USA: Brunner/Mazel, Inc.

Cho, H., Hallfors, D. D., \& Sanchez, V. (2005). Evaluation of a high school peer group intervention for atrisk youth. Journal of Abnomal Child Psychology, 33, 363-374.

Cicchetti, D., \& Hinshaw, S. P. (2002). Editorial: Prevention and intervention science: Contributions to developmental theory. Development and Psychopathology, 14, 667-671.

Coie, J. D., \& Dodge, K. A. (1998). Aggression and antisocial behavior. In W. Damon \& N. Eisenberg (Eds.), Handbook of child psychology: Social, emotional, and personality development (vol. 3, pp. 779862). New York, NY: Wiley.

Coie, J. D., \& Jacobs, M. R. (1993). The role of social context in the prevention of conduct disorder. Development and Psychopathology, 5, 263-275.

Coie, J. D., \& Koeppl, G. (1990). Adapting intervention to the problems of aggressive and disruptive rejected children. In S. A. Asher \& J. D. Coie (Eds.), Peer rejection in childhood (pp. 309-337). New York: Cambridge University Press.

Coie, J. D., \& Kupersmidt, J. D. (1983). A behavioral analysis of emerging social status in boys' groups. Child Development, 54, 1400-1416.

Coie, J., Terry, R., Zabriski, A., \& Lochman, J. (1995). Early adolescent social influences on delinquent behavior. In J. McCord (Ed.), Coercion and punishment in long-term perspectives (pp. 229-244). New York, NY: Cambridge University Press.

Conduct Problems Prevention Research Group (1992). A developmental and clinical model for the prevention of conduct disorders: The fast track program. Development and Psychopathology, 4, 509-527. 
Conduct Problems Prevention Research Group (1999). Initial impact of the fast track prevention trial for conduct problems: Ii. Classroom effects. Journal of Consulting and Clinical Psychology, 67, 648-657.

Conduct Problems Prevention Research Group (2002). Evaluation of the first 3 years of the FAST TRACK prevention trial with children at high risk for adolescent conduct problems. Journal of Abnormal Child Psychology, 30, 19-35.

Conduct Problems Prevention Research Group (2004). The effects of the fast track program on serious problem outcomes at the end of elementary school. Journal of Clinical Child and Adolescent Psychology, 33, 650-661.

Costello, E. J., Mustillo, S., Erkanli, A., Keeler, G., \& Angold, A. (2003). Prevalence and developmental course of psychiatric disorders in childhood and adolescence. Archives of General Psychiatry, 60, 837-844.

Deater-Deckard, K. (2001). Annotation: Recent research examining the role of peer relationships in the development of psychopathology. Journal of Child Psychology and Psychiatry, 42, 565-579.

DeRosier, M. E., Kupersmidt, J. B., \& Patterson, C. J. (1994). Children's academic and behavioral adjustment as a function of the chronicity and proximity of peer rejection. Child Development, 65, 1799-1813.

Dishion, T. J. (1990a). The family ecology for boys' peer relations in middle childhood. Child Development, $61,874-892$.

Dishion, T. J. (1990b). Peer context of troublesome behavior in children and adolescents. In P. Leone (Ed.), Understanding troubled and troublesome youth (pp. 128-153). Beverly Hills, CA: Sage.

Dishion, T. J., \& Andrews, D. W. (1995). Preventing escalation in problem behaviors with high-risk young adolescents: Immediate and 1-year outcomes. Journal of Consulting and Clinical Psychology, 63, 538-548.

Dishion, T. J., Andrews, D. W., \& Crosby, L. (1995a). Antisocial boys and their friends in early adolescence: Relationship characteristics, quality, and interactional process. Child Development, 66, 139-151.

Dishion, T. J., Capaldi, D., Spracklen, K. M., \& Li, F. (1995b). Peer ecology of male adolescent drug use. Development and Psychopathology, 7, 803-824.

Dishion, T. J., \& Dodge, K. A. (2005). Peer contagion in interventions for children and adolescents: Moving towards an understanding of the ecology and dynamics of change. Journal of Abnormal Child Psychology, 33, 395-400.

Dishion, T. J., French, D. C., \& Patterson, G. R. (1995). The development and ecology of antisocial behavior. In D. Cicchetti \& D. J. Cohen (Eds.), Manual of developmental psychopathology (pp. 421-471). New York, NY: John Wiley \& Sons.

Dishion, T. J., McCord, J., \& Poulin, F. (1999). When interventions harm: Peer groups and problem behavior. American Psychologist, 54, 755-764.

Dishion, T. J., Poulin, F., \& Burraston, B. (2001). Peer group dynamics associated with iatrogenic effects in group interventions with high-risk young adolescents. New Directions for Child and Adolescent Development, 79-92.

Dishion, T. J., Spracklen, K. M., Andrews, D. W., \& Patterson, G. R. (1996). Deviancy training in male adolescents friendships. Behavior Therapy, 27, 373-390.

Dodge, K. A. (1983). Behavioral antecedents of peer social status. Child Development, 54, 1386-1399.

Dodge, K. A., Dishion, T. J., \& Lansford, J. E. (2006). Deviant peer influences in intervention and public policy for youth.

Dodge, K. A., Lansford, J. E., Burks, V. S., Bates, J. E., Pettit, G. S., Fontaine, R., et al. (2003). Peer rejection and social information-processing factors in the development of aggressive behavior problems in children. Child Development, 74, 374-393.

Dolan, L. J., Kellam, S. G., Brown, C. H., Werthamer-Larsson, L., Rebok, G. W., Mayer, L. S., et al. (1993). The short-term impact of two classroom-based preventive interventions on aggressive and shy behaviors and poor achievement. Journal of Applied Developmental Psychology, 14, 317-345.

Elliott, D. S., Huizinga, D., \& Ageton, S. S. (1985). Explaining delinquency and drug use. Beverly Hills, CA: Sage.

Estell, D. B., Cairns, R. B., Farmer, T. W., \& Cairns, B. D. (2002). Aggression in inner-city early elementary classrooms: Individual and peer-group configurations. Merrill-Palmer Quarterly, 48, 52-76.

Farrington, D. P., Loeber, R., Elliott, D. S., Hawkins, J. D., Kandel, D. B., Klein, M. W., et al. (1990). Advancing knowledge about the onset of delinquency and crime. In B. B. Lahey \& A. E. Kazdin (Eds.), Advances in clinical child psychology (vol. 13, pp. 283-342). New York: Plenum Press.

Farver, J. A. M. (1996). Aggressive behavior in preschoolers' social networks: Do birds of a feather flock together? Early Childhood Research Quarterly, 11, 333-350.

Feldman, R. A., Caplinger, T. E., \& Wodarski, J. S. (1983). The St. Louis conundrum: The effective treatment of antisocial youths. Englewood Cliffs, NJ: Prentice-Hall.

Foster, E. M., \& Jones, D. E. (2005). The high costs of aggression: Public expenditures resulting from conduct disorder. American Journal of Public Health, 95, 1767-1772. 
Gatti, U., Tremblay, R. E., Vitaro, F., \& McDuff, P. (2005). Youth gangs, delinquency and drug use: A test of the selection, facilitation, and enhancement hypotheses. Journal of Child Psychology and Psychiatry, 46, 1178-1190.

Gottfredson, D. C., Gerstenblith, S. A., Soule, D. A., Womer, S. C., \& Lu, S. (2004). Do after school programs reduce delinquency? Prevention Science, 5, 253-266.

Gottfredson, M. R., \& Hirschi, T. (1990). A general theory of crime. Stanford, CA: Stanford University Press.

Greenberg, M. T., \& Kusché, C. A. (1993). Promoting social and emotional development in deaf children: The paths project. Seattle: University of Washington Press.

Greenberg, M. T., Kusché, C. A., \& Mihalic, S. F. (1998). Promoting alternative thinking strategies (paths). Boulder, CO: Center for the Study and prevention of Violence.

Howe, G. W., Reiss, D., \& Yuh, J. (2002). Can prevention trials test theories of etiology? Development and Psychopathology, 14, 673-694.

Ialongo, N., Poduska, J., Werthamer, L., \& Kellam, S. (2001). The distal impact of two first-grade preventive interventions on conduct problems and disorder in early adolescence. Journal of Emotional and Behavioral Disorders, 9, 146-160.

Ialongo, N. S., Werthamer, L., Kellam, S. G., Brown, C. H., Wang, S., \& Lin, Y. (1999). Proximal impact of two first-grade preventive interventions on the early risk behaviors for later substance abuse, depression, and antisocial behavior. American Journal of Community Psychology, 27, 599-641.

Institute of Medicine (1994). Reducing risks for mental disorders: Frontiers for preventive intervention research. Washington DC: National Academy Press.

Kazdin, A. E. (1996). Dropping out of child psychotherapy treatment: Issues for research and implications for practice. Clinical Child Psuchology and Psychiatry, 1, 133-156.

Kazdin, A. E. (1997). Practitioner review: Psychosocial treatments for conduct disorder in children. Journal of Child Psychology and Psychiatry, 38, 161-178.

Keiley, M. K., Bates, J. E., Dodge, K. A., \& Pettit, G. S. (2000). A cross-domain growth analysis: Externalizing and internalizing behaviors during 8 years of childhood. Journal of Abnormal Child Psychology, 28, 161-179.

Kellam, S. G., Ling, X., Merisca, R., Brown, C. H., \& Ialongo, N. (1998). The effect of the level of aggression in the first grade classroom on the course and malleability of aggressive behavior into middle school. Development and Psychopathology, 10, 165-185.

Kellam, S. G., Rebok, G. W., Ialongo, N., \& Mayer, L. S. (1994). The course and malleability of aggressive behavior from early first grade into middle school: Results of a developmental epidemiologically- based preventive trial [published erratum appears in j child psychol psychiatry 1994 jul;35(5):983]. Journal of Child Psychology and Psychiatry, 35, 259-281.

Kusché, C. A., \& Greenberg, M. T. (1994). The paths curriculum. Seattle, WA.

Lacourse, E., Nagin, D., Tremblay, R. E., Vitaro, F., \& Claes, M. (2003). Developmental trajectories of boys' delinquent group membership and facilitation of violent behaviors during adolescence. Development and Psychopathology, 15, 183-197.

Ladd, G. W. (1983). Social networks of popular, average and rejected children in school settings. MerrillPalmer Quarterly, 29, 283-307.

Lavallee, K. L., Bierman, K. L., Nix, R. L., \& The Conduct Problems Prevention Research Group (2005). The impact of first-grade "friendship group" experiences on child social outcomes in the fast track program. Journal of Abnormal Child Psychology, 33, 307-324.

Lösel, F., \& Beelmann, A. (2003). Effects of child skills training in preventing antisocial behavior: A systematic review of randomized evaluations. Annals of the American Academy of Political and Social Science, 587, 84-109.

Mager, W., Milich, R., Harris, M. J., \& Howard, A. (2005). Intervention groups for adolescents with conduct problems: Is aggregation harmful or helpful? Journal of Abnormal Child Psychology, 33, 349-362.

Mahoney, J. L., Stattin, H., \& Lord, H. (2004). Unstructured youth recreation centre participation and antisocial behaviour development: Selection influences and the moderating role of antisocial peers. International Journal of Behavioral Development, 28, 553-560.

Mahoney, J. L., Stattin, H., \& Magnusson, D. (2001). Youth recreation centre participation and criminal offending: A 20-year longitudinal study of swedish boys. International Journal of Behavioral Development, 25, 509-520.

Metropolitan Area Child Study Research Group (2002). A cognitive-ecological approach to preventing aggression in urban settings: Initial outcomes for high-risk children. Journal of Consulting and Clinical Psychology, 70, 179-194.

Miller-Johnson, S., Coie, J. D., Maumary-Gremaud, A., \& Bierman, K. (2002). Peer rejection and aggression and early starter models of conduct disorder. Journal of Abnormal Child Psychology, 30, 217-230. 
Miller-Johnson, S., Coie, J. D., Maumary-Gremoud, A., Lochman, J. E., \& Terry, R. (1999). Relationship between childhood peer rejection and aggression and adolescent delinquency severity and type among african american youth. Journal of Emotional and Behavioral Disorders, 7, 137-146.

Moffitt, T. E., Caspi, A., Dickson, N., Silva, P., \& Stanton, W. (1996). Childhood-onset versus adolescentonset antisocial conduct problems in males: Natural history from ages 3 to 18 years. Development and Psychopathology, 8, 399-424.

Moffitt, T. E., Caspi, A., Harrington, H., \& Milne, B. J. (2002). Males on the life-course-persistent and adolescencelimited antisocial pathways: Follow-up at age 26 years. Development and Psychopathology, 14, 179-207.

Patterson, G. R., DeBaryshe, B. D., \& Ramsey, E. (1989). A developmental perspective on antisocial behavior. American Psychologist, 44(2), 329-335.

Patterson, G. R., Dishion, T. J., \& Yoerger, K. (2000). Adolescent growth in new forms of problem behavior: Macro- and micro-peer dynamics. Prevention Science, 1, 3-13.

Petras, H., Kellam, S., Brown, C. H., \& Ialongo, N. S. (2003). Effects of a universal first grade classroom based preventive intervention on the developmental paths and prevention of anti-social personality disorder in young adulthood. Paper presented at the Society for Prevention Research 11th Annual Meeting, Research to Policy, Washington DC.

Poulin, F., Dishion, T. J., \& Burraston, B. (2001). 3-year iatrogenic effects associated with aggregating high-risk adolescents in cognitive-behavioral preventive interventions. Applied Developmental Science, 5, 214-224.

Putallaz, M., \& Wasserman, A. (1990). Children's entry behavior. In S. R. Asher \& J. D. Coie (Eds.), Peer rejection in childhood (pp. 60-89). New York: Cambridge University Press.

Reid, J. B., Eddy, J. M., Fetrow, R. A., \& Stoolmiller, M. (1999). Description and immediate impacts of a preventive intervention for conduct problems. American Journal of Community Psychology, 27, 483-517.

Reynolds, A. J., Ou, S. R., \& Topitzes, J. W. (2004). Paths of effects of early childhood intervention on educational attainment and delinquency: A confirmatory analysis of the chicago child-parent centers. Child Development, 75, 1299-1328.

Rubin, K. H., Bukowski, W., \& Parker, J. G. (1998). Peer interactions, relationships, and groups. In W. Damon \& N. Eisenberg (Eds.), Handboek of child psychology: Social emotional and personality development (vol. 3, pp. 619-700). New York: Wiley.

Shrout, P. E., \& Bolger, N. (2002). Mediation in experimental and nonexperimental studies: New procedures and recommendations. Psychological Methods, 7(4), 422-445.

Snyder, J., Horsch, E., \& Childs, J. (1997). Peer relationships of young children: Affiliative choices and the shaping of aggressive behavior. Journal of Clinical Child Psychology, 26, 145-156.

Snyder, J., Prichard, J., Schrepferman, L., Patrick, M. R., \& Stoolmiller, M. (2004). Child impulsivenessinattention, early peer experiences, and the development of early onset conduct problems. Journal of Abnormal Child Psychology, 32, 579-594.

Thrasher, F. (1936). The boys' club and juvenile delinquency. American Journal of Sociology, 41, 66-80.

van Lier, P. A. C., Muthén, B. O., van der Sar, R. M., \& Crijnen, A. A. M. (2004). Preventing disruptive behavior in elementary schoolchildren: Impact of a universal, classroom based intervention. Journal of Consulting and Clinical Psychology, 72, 467-478.

van Lier, P. A. C., Vitaro, F., Wanner, B., Vuijk, P., \& Crijnen, A. A. M. (2005a). Gender differences in the developmental links between antisocial behavior, friends' antisocial behavior and peer rejection in childhood: Results from two cultures. Child Development, 76, 841-855.

van Lier, P. A. C., Vuijk, P., \& Crijnen, A. A. M. (2005b). Understanding mechanisms of change in the development of antisocial behavior: The impact of a universal intervention. Journal of Abnormal Child Psychology, 33, 521-535.

Verhulst, F. C., \& van der Ende, J. (1997). Factors associated with child mental health service use in the community. Journal of the American Academy of Child and Adolescent Psychiatry, 36, 901-909.

Vitaro, F., Brendgen, M., Pagani, L., Tremblay, R. E., \& McDuff, P. (1999). Disruptive behavior, peer association, and conduct disorder: Testing the developmental links through early intervention. Development and Psychopathology, 11, 287-304.

Vitaro, F., Tremblay, R. E., Kerr, M., Pagani, L., \& Bukowski, W. M. (1997). Disruptiveness, friends' characteristics, and delinquency in early adolescence: A test of two competing models of development. Child Development, 68, 676-689.

Warren, K., Schoppelrey, S., Moberg, D. P., \& McDonald, M. (2005). A model of contagion through competition in the aggressive behaviors of elementary school students. Journal of Abnormal Child Psychology, 33, 283-292. 